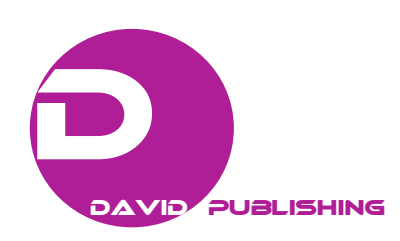

\title{
A Model for Predictable Capacity of a Container Terminal State: A System Dynamics Approach
}

\author{
Cláudio J. M. Soares ${ }^{1}$ and Hostilio Xavier Ratton Neto ${ }^{2}$ \\ Transport Engineering Program, Universidade Federal do Rio de Janeiro, Rio de Janeiro 21941-914, Brazil
}

\begin{abstract}
Low performance of operational practices and wrong perceptions on demand forecast cause improper investments on new facilities for containers terminals, without taking into account the best use of their available resources. Accordingly, it would be desirable to model dynamic behaviour among demand, capacity and productivity of container terminal services, like reception, storage and distribution, to forecast their performances faced to demand evolution with time. This paper presents a system dynamic model to evaluate impacts from demand variations on 18 container terminals associated to ABRATEC (Associação Brasileira dos Terminais de Contêineres de Uso Público (in English: Brazilian Association of Public Container Terminals)) and their response capability to compensate demand growth with increasing productivity. The behaviour of the developed dynamic models was demonstrated by means of simulations carried out with the Vensim Standard 5.6d system dynamics software.
\end{abstract}

Key words: Capacity, productivity, system dynamics, container terminal.

\section{Introduction}

The operational dynamics of a container terminal is governed by market perceptions and from decisions that arise from those perceptions. Under that perspective, according to Sterman [1], the interpretation of the real world not only drives our decisions but also alter our mental model about the reality creating different decision rules and new strategies. Thus, our decisions alter our environment, leading to new decisions that trigger side effects, consequently delay reactions, changes goals and bring the intervention of others in the system. For example, the problem of berth scheduling for optimizing vessels arrival time in the containers terminals with the terminal yard organization is highly complex, not only operationally but administratively in order to cope with all commercial and logistics demands [2]. However, the complexity lies in finding the best solution out of an astronomical number of possibilities.

Corresponding author: Hostílio Xavier Ratton Neto, Dr., research fields: rail transport planning and operation, intermodality, transport terminals and urban logistics.
According to Sterman [1], the dynamics complexity, in contrast, can arise even in simple systems with low combinatorial complexity due to the complexity arises from the interactions of the agents over time.

Even Kim, K. and Kim, H. [3, 4] highlighted the difficulty in developing simulations to port operations due to the dynamicity of the system. There are some simulation methods able to describe operational features, along with different levels of complexity, and reasonably explain that industry, despite its dynamic complexity. Among those methods, the system dynamics is known as a flexible modelling one and is able to effectively simulate different scenarios and describe their results related to the perception and decision-making processes undertaken by the decision-makers of the industry in short, medium and long terms.

Thus, in this paper, to assess the impact of the demand variation on the container terminal state capacity and productivity, the methodology based in system dynamics was chosen. The current literature, in terms of simulation based on system dynamics, does not cover the Brazilian containers terminal state behaviour to cope demand throughout the calibration 
capacity and productivity. Hence, this paper focuses on the simulation by itself supported by the essential academic literature.

By the other side, the system dynamics-based simulation is experiment for testing mental model and performance effects and is a conceptual representation of the structure of an external system used by people to describe, explain and predict a system's behaviour. Mental models have been commonly used in system dynamics and systems thinking literature, such as models used by Forrester [5], Senge [6], Doyle and Ford [7], and Sterman [1]. Hence, the models built in this paper are based in the theoretical principles of system dynamics toward the perception of the author in how the Brazilian containers terminal state works dynamically. The principals of system dynamics validation methodology also validate those models.

\section{The Data Collection}

According to Evangelista [8], the liner shipping industry is notorious for poor communication among its players and mediocre information management connected with a wide range of logistical deficiencies. Information is the main factor that affects the dynamics features of a logistics system and, according to Davis [9], the uncertainty is the key element that impact the effectiveness of a supply chain.

Historically, within the scope of logistics chain, the seaports industry is unique. Comparing with others industries, the seaports industry is the late one to adopt technological innovation to its operational control and commercial transaction. This is associated with the traditional resistance to release data and information. Due to such constraint, many times, to investigate the impact of demand fluctuation over a container terminal state based in public data could not be viable or even reliable.

However, such research is possible when the data collected is less sensitive to unreliability such as container traffic, which could be validated throughout the seaports stakeholders, the technical capacity of a terminal, its project productivity and the perception of the decision-makers over operational, logistics, commercial and bureaucratic issues.

In this research, the method adopted involved a number of data capturing techniques, including interviews and observations.

The operational and statistical data was collected throughout the container terminal state, also attaining the executive's perception before the exogenous parameters like time to project demand and time to adjust capacity to cope with demand. Reference points for decision-making as planning horizon and operational non-linear relationships as the effect of density on productivity were also considered to modelling the behaviour pattern of the container terminal state studied.

In possession of those data and added by field observations, it was possible to develop a model which dynamically represents the system operational behaviour over time and how the system responses to market pressure.

\section{System Dynamics Methodology}

Given the methodological difficulties of research on productivity analysis of a container terminal state, this study adopts a computer simulation methodology to analyze the growth of the terminals capacity and finally their productivity, since a computer simulation model could help users of the model easily implement the potential scenarios in a computer, make themselves familiar with the dynamics situations of interest, and test different strategies to cope with demand variation. In other words, the computer simulation model for the productivity analysis can be useful as a learning tool.

Among the several computer simulation methodologies, the system dynamics modelling is chosen for this research. System dynamics is a methodology to the construction of simulation models to complex systems. It was formulated by Jay Forrester [5] in the early 1960s at MIT (Massachusetts 
Institute of Technology) Sloan School of Management and enhanced the understanding of complex system to assist businesses and government organizations in strategy development, analysis of policy options and analysis of dynamic processes in which capturing information flow and feedback are important considerations. A system dynamics model captures the factors that affect the behaviour of the system in causal-loop diagrams represented by stocks and flows structure of information and materials. These representations help to describe how the multiple interdependent components of a system interact among themselves in multiple feedback loops that are highly dynamic, involving multiple feedback processes, non-linear relationships, operational data and managerial perceptions that drive to decisions that will alter the system environment. Hence, system dynamics can be properly applied in systems whenever their components can be expressed as variable behaviours through time as we can see in industrial systems, engineering process systems, dynamic urban development systems, corporate strategy development system, biology systems, medicine and so on.

The dynamic of containers seaport is highly complex. All management decisions and strategies are involved in processes related to the use of its assets, reflecting the effect of these decisions on the financial performance of the business. Thus, the system dynamics are very helpful in explaining the relationship between the internal and external variables to a container terminal system.
The structure (Fig. 1) shows a simple diagram of the process flow of containers in a seaport container terminal.

\section{Model Validation Methodology}

It is important that a model based on system dynamics can not only represent virtually the real world, but also reproduce and predict its behaviour, which is to explain how that behaviour is generated and suggest how to change the existing behaviour.

System dynamics models are by nature descriptive, which illustrates how the real system actually operates in some aspects. Generating precise outputs is not sufficient for the validity of the behaviour of the model. What is crucial is the validity of the internal structure of the model that must be able not only to reproduce and predict its behaviour, but also explain how the behaviour is generated, and possibly suggest ways of changing the existing behaviour. However, It can not be entirely objective, formal and quantitative to validate the external and the internal structures of the model. Sometimes it can be subjective, informal and qualitative. Therefore, it is hard to formally validate a system dynamics model $[11,12]$.

According to Barlas [12] and Forrester [5], given the difficulty of model validation in system dynamics, it is widely accepted that model validation is a process of confidence in the utility of the model gradually, by constantly confronting the model with data and experts opinion. According to Oliva [13, 14], validity of a system dynamics model can not be discussed without reference to a specific purpose, hence, model validation

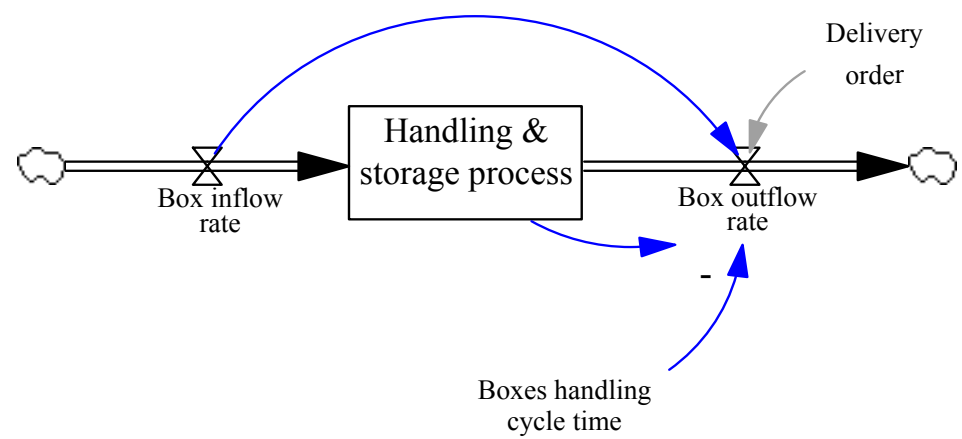

Fig. 1 Basic stock and flow model in a container terminal (overview built based on the concepts of Morecroft, J. [10]). 
is a gradual process of confidence building with respect to purpose of model, rather than a binary accept/reject divisions.

To summarize the model validation in system dynamics, Barlas [12] proposed two steps regarding to the model validation process for a system dynamic model as below (Table 1):

- structure validity;

- behaviour validity.

For an industry state modelled by systems dynamic methodology, beyond the logical structure validation, it must also be validated behaviourally through observations and market data collection that will generate a process of empirical calibration, which will be validated via sensitivity tests.

In order to calibrate the model, input data should be collected first. There are five types of data to be collected:

- Endogenous input variables;

- Exogenous input variables;

- Reference points for decision-making;

- Information delay time;

- Non-linear relationships.

Those data are collected from various industry source and interviews with the industry decisions-makers.

After collecting the real data, the model structures and key parameters were consulted with industry seniors' executives to ensure the structure validity of the model and start the empirical calibration process.

For non-linear variables, when their values are out of the knowledge of industry seniors executives, acceptable values of estimated parameters must be applied in order to keep showing the model behaviour in accordance with the real world. Thus, for the validity of the model, real data must be used and market parameters reasonably estimated.

\section{Empirical Calibration and Behaviour Reproduction Test}

After collecting the data for exogenous parameters, the model can now be calibrated to the real industry data in order to ensure the behaviour validity. In order words, for the behaviour validity, simulation results from the model should successfully regenerate the behaviour of the historical industry data series.

Many tools are available to assess a model capability to reproduce the behaviour of the system in the real world. In this research, it was used the coefficient of determination (R2) as measure of fit in order to show the degree of success of the model that simulates the historical behaviour of the industry variables.

The coefficient of determination, by itself, does not validate the model, which depends on error testing that indentifies how reliable the model is and its suitability to the real world throughout the sample period.

According to Sterman [1], large errors may be due to a poor model or a large amount of random noise in the data, reflecting the random or cyclical shocks in one of the data series and not present in the others

Table 1 Validation process for models in system dynamics [1].

\begin{tabular}{|l|}
\hline Building the dynamic model \\
\hline $\begin{array}{l}\text { Objective: This step is to develop a dynamic model, based on mental model through which the developer believes that the model } \\
\text { reproduces the structure and behaviour of the real world. }\end{array}$ \\
\hline Structure validity \\
\hline $\begin{array}{l}\text { Objective: In the structure validity, the model should explain the real system with causal links embedded in the model. The validity of } \\
\text { the model structure is assessed by direct comparison with the knowledge about the real system structure. Causal loop diagrams are } \\
\text { often useful ways of testing the structure validity. }\end{array}$ \\
\hline Behaviour validity \\
\hline $\begin{array}{l}\text { Objective: The validity of the behavioural model is measured by how far the model faithfully reproduces the behaviour of the system } \\
\text { as in the real world. According to Barlas [12], it is crucial to understand that the emphasis is on the pattern of behaviour such as } \\
\text { periods, frequencies, trends, etc., and not on specific events. Once the model has confirmed the default behaviour of the system as it is } \\
\text { in the real world, it can be considered as passing the behaviour validity test. }\end{array}$ \\
\hline
\end{tabular}


captured in the real world. Hence, to the behavioural assessment of a model, it is important not just to know the sources of error but the total size of the error, because even a total error may be large if a mode of behaviour in the real system is deliberately excluded as irrelevant to the model purpose.

Several statistical methods help to decompose the errors. In this research, it is used the Theil inequality statistics that provide the interpretation of the errors break-down into systematic and unsystematic components, dividing the MSE (mean square error) into three components: bias, unequal variation and unequal co-variation.

In this research, all discrepancies believed significant leaded to model revision and it was not introduced neither fudge factors nor exogenous variables whose sole function would be to improve the historical fit of the model.

\section{Vensim 5.6d as Simulation Tool}

Simulation software for system dynamics environment as Vensim Software (Ventana ${ }^{\circledR}$ Systems, Inc.) are used to model complex systems and to test decision-making policy based on the model. The Vensim Software is used as simulation tool in several industry, such as energy, manufacturing, aerospace, financial, information and communications technology, pharmaceuticals, petrochemical, retail, agriculture, fishing, automotive, government and military. In this research, it was used the Vensim Standard for Windows ${ }^{\circledR}$, version 5.6d.

The Vensim ${ }^{\circledR}$ has functions to set the dynamic equilibrium of the models. Through those functions, the equations are constructed that govern the dynamic relationship between variables that represent stocks and flows of materials or information. In this research, the following predefined functions were used:

(1) If then else (condition $\mathrm{X}$ and $\mathrm{Y}$ ): returns $\mathrm{X}$ if cond (condition) is non-zero, otherwise $\mathrm{Y}$; returns first value $(\mathrm{X})$ if condition is true, second value $(\mathrm{Y})$ if condition is false. Cond must be a Boolean expression or an expression or variable that can be interpreted as Boolean. Only the value returned is evaluated, the other value could be an expression that would lead to an error;

(2) Smooth ( $\mathrm{X}$ and $\mathrm{T}$ ): returns a first order exponential smooth of $\mathrm{X}$ over time $\mathrm{T}$. The smooth function is commonly used to take time averages and represent expectations. It is different from "if then else" in that it has time behavior built into it;

(3) Integ (R and N): performs numerical integration of $\mathrm{R}$ starting at $\mathrm{N}$ (defines a level); returns the integral of the rate. The rate is numerically integrated. The initial value is the value of the variable on the left-hand side of the equation at the start of the simulation;

(4) Forecast (I, A and H): forecast for I over the time horizon $\mathrm{H}$ using an averaging time $\mathrm{A}$;

(5) Lookup area (lookup, start and end): returns the area under a lookup table between start and end in a non-linear relation. This function is useful for normalizing lookups in problems such as determining the intensity of effort in a project given the fraction of work that has been completed.

\section{Dynamic Model of Capacity}

The dynamic model of container terminals capacity simulates the terminal response to demand over time through the expansion of its super and infrastructure.

The model developed took as baseline of the inventory management model, "stock-management system" [1], which is widely accepted. However, due to the peculiar characteristics of the port industry, the Sterman-based model was set for this industry.

In this model, the decision-makers are assumed to calculate the investment for adjusting capacity mainly on the bases of projected demand and the desired capacity.

The inputs to this model are real demand, planning horizon, desired capacity and annual capacity growth rate. 


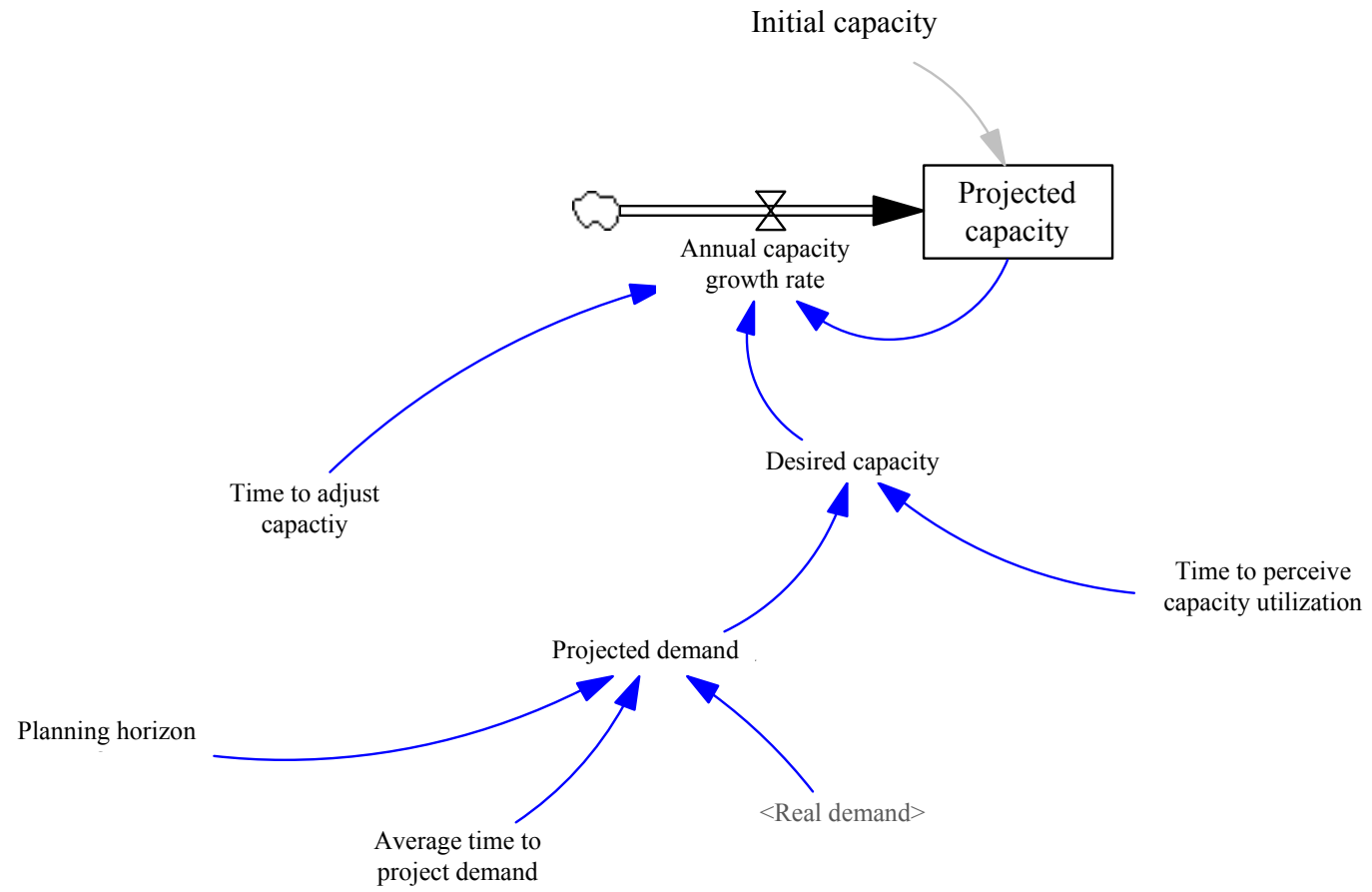

Fig. 2 Structure of capacity model.

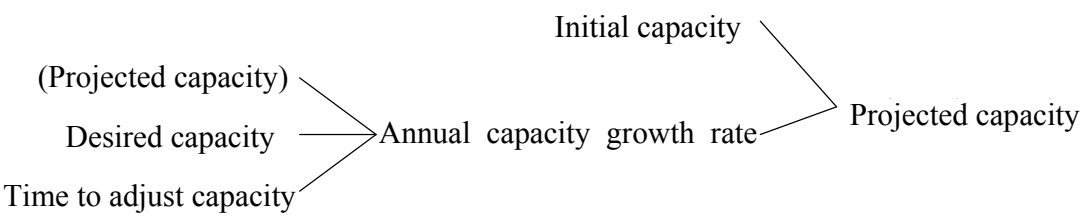

Fig. 3 Causes tree of capacity model.

The structure (Fig. 2) represents the dynamic model for the container terminals capacity.

Detailed equations of this model are provided below:

(1) Desired capacity = smooth (projected demand, time to perceive capacity utilization);

(2) Projected capacity = integ (annual capacity growth rate, initial capacity);

(3) Projected demand = forecast (real demand, average time to project demand, planning horizon);

(4) Annual capacity growth rate $=$ if then else (desired capacity $\leq$ projected capacity, 0 , (desired capacity-projected capacity)/time to adjust capacity).

Detailed causes tree of this model is provided in Fig. 3.

According to the knowledge about the real system and the specific purpose of the model, the model structure and their algorithms seek to demonstrate the validity of its dynamic structure [15].

\subsection{Real Dynamic Capacity of the Containers Terminal State Assessed}

The real dynamic capacity of a container terminal is defined by its infrastructure aspects, handling system and the time spent in logistics operations. Subject extensively reviewed in international terms by Marlow and Paixão [16, 17], Rios and Maçada [18, 19] and Thomas [20, 21], with Santos and Haddad [22] toward Brazilian market, and in broadest sense by Robinson [23], and also regarding supply chain as a whole by Prater et al. [24]. Through assessing those aspects, it was possible to disclose the annual dynamic capacity of 18 container terminals associated to ABRATEC (Associação Brasileira dos Terminais de Contêineres de Uso Público (in English: Brazilian Association of Public Container Terminals)). 
Table 2 shows the findings in TEU (20-foot equivalent unit) and boxes handled.

\subsection{The Behaviour Accuracy of the Model}

After passing the structure validity test, a model should be tested for behaviour validity. The behaviour is to measure how accurately the model can reproduce the major behaviour patterns exhibited in the real system. According to Barlas [12], it is crucial to note that the emphasis is on the pattern prediction (periods, frequency, trends and so), rather than points (events) prediction. As long as a system dynamics model can reproduce the patterns of the real system, it is considered as passing the behaviour validity test.

In the container terminals capacity model, the mainly endogenous parameters are real demand, desired capacity, projected demand and the annual capacity growth rate, while the mainly exogenous parameters to be considered in the model in order to assess the terminals state adjustment capacity are initial capacity, the time for decision-makers to adjust the terminals capacity based on their perception of the terminal capacity utilization, planning horizon and the average time to project demand.

The data collected show the endogenous and exogenous parameters, within which are defined the variables of decision points and time perception of decision-makers, as provided below:

(1) decisions points:

- planning horizon;

(2) time perception:

- time to adjust capacity;

- average time to project demand;

- time to perceive the capacity utilization.

The numerical result for the behaviour validity test is shown in Table 3.

The exogenous input variables considered for the model are presented in Table 4.

Fig. 4 shows the real capacity of the terminals over time compared with the projected capacity over time obtained by the model simulation.

\subsection{Behaviour Validity Test of the Container Terminal State Capacity Model}

The graph in Fig. 4 shows the simulation model tracking the historical data of the system in the assessed period. The results of the behavioural test are shown in Table 5.

The simulation results show that the model tracks the historical system data quite well. Thus, the correlation of the real capacity to projected capacity is 0.935. In other words, the correlation clearly indicates the symmetry behaviour of the values obtained in the simulation model with the values collected in the real world. The MAPE between the simulated and actual data are less than $7 \%$, indicating a close fit of the model to the actual behaviour of the containers terminal state. In addition, the low bias and variation components of the Theil's inequality statistics indicate that errors are unsystematic.

It is possible to observe in the Fig. 4 that the data variation shown in the real world data are not reproduced in the simulation result, indicating the presence of "noise" caused by "random shocks" or cyclic behaviour.

Many industries and systems, including the maritime industry with its international and logistics transport systems, quite often tend to amplify "random shocks" as response to increase of demand (bullwhip effect $\left.^{1}\right)$.

\section{The Dynamic Model of Productivity}

The dynamic model of container terminals productivity simulates the operational terminals capacity to respond to the market pressure through containers delivery capacity while the terminals infrastructure goes through the expansion capacity over time.

The inputs to this model are real demand and projected capacity. However, the terminals face a

\footnotetext{
${ }^{1}$ The bullwhip effect occurs when the demand order variabilities in the supply chain are amplified as they move up the chain. The concept is created to help supply chain professionals to effectively counteract the bullwhip effect.
} 
Table 2 Container terminals capacity over time.

\begin{tabular}{|c|c|c|c|c|c|c|c|c|c|c|c|c|c|}
\hline Year & 2000 & 2001 & 2002 & 2003 & 2004 & 2005 & 2006 & 2007 & 2008 & 2009 & 2010 & 2011 & 2012 \\
\hline $\begin{array}{l}\text { Total } \\
\text { capacity } \\
\text { (TEU/year) }\end{array}$ & $2,365,200$ & $2,619,240$ & $3,622,260$ & $4,409,565$ & $5,017,603$ & $5,380,048$ & $5,934,118$ & $6,355,283$ & $7,166,574$ & $7,519,164$ & $8,167,408$ & $10,015,311$ & $10,555,029$ \\
\hline $\begin{array}{l}\text { Total } \\
\text { capacity } \\
\text { (box/year) } \\
\end{array}$ & $1,576,800$ & $1,746,160$ & $2,414,840$ & $2,939,710$ & $3,345,069$ & $3,586,699$ & $3,956,079$ & $4,236,856$ & $4,777,716$ & $5,012,776$ & $5,444,939$ & $6,676,874$ & $7,036,686$ \\
\hline \multicolumn{14}{|c|}{ Source: ABRATEC. } \\
\hline \multirow{2}{*}{$\begin{array}{l}\text { Year } \\
\text { Projected } \\
\text { capacity } \\
\text { (box/year) } \\
\end{array}$} & 2000 & 2001 & 2002 & 2003 & 2004 & 2005 & 2006 & 2007 & 2008 & 2009 & 2010 & 2011 & 2012 \\
\hline & $1,576,000$ & $1,638,000$ & $1,951,000$ & $2,575,000$ & $3,194,000$ & $3,705,000$ & $4,133,000$ & $4,516,000$ & $4,516,000$ & $4,879,000$ & $5,235,000$ & $5,588,000$ & $5,941,000$ \\
\hline $\begin{array}{l}\text { Real } \\
\text { capacity } \\
\text { (box/year) }\end{array}$ & $1,576,800$ & $1,746,160$ & $2,414,840$ & $2,939,710$ & $3,345,069$ & $3,586,699$ & $3,956,079$ & $4,236,856$ & $4,236,856$ & $4,777,716$ & $5,012,776$ & $5,444,939$ & $6,676,874$ \\
\hline
\end{tabular}

\section{Table 4 The exogenous input variables.}

\begin{tabular}{|l|l|l|l|}
\hline Variables & Value & Unit & Description and source \\
\hline Initial capacity & $1,576,800$ & Box/year & Initial dynamics capacity of the terminal state according to ABRATEC [25, 26] \\
\hline Time to adjust capacity & 1.55 & Year & $\begin{array}{l}\text { Time over which the decision-makers consider between the time of decision to expand the capacity and the } \\
\text { availability of this capability: } \pm 18 \text { months }\end{array}$ \\
\hline $\begin{array}{l}\text { Time to perceive the capacity } \\
\text { utilization }\end{array}$ & 0.25 & Year & $\begin{array}{l}\text { Time for decision-makers to confirm the current capacity utilization trend: It is estimated to be around three } \\
\text { months from the calibration process }\end{array}$ \\
\hline Planning horizon & 3 & Year & $\begin{array}{l}\text { The number of years that decision-makers consider when they estimate desired terminal capacity in the future } \\
\text { based in a projected demand. Value derived from empirical calibration and confirmed with industry executives }\end{array}$ \\
\hline Average time to project demand & 1 & Year & $\begin{array}{l}\text { Averaging time for past demand used in the projected demand. It is assumed to be one year according to the } \\
\text { industry executives }\end{array}$ \\
\hline
\end{tabular}




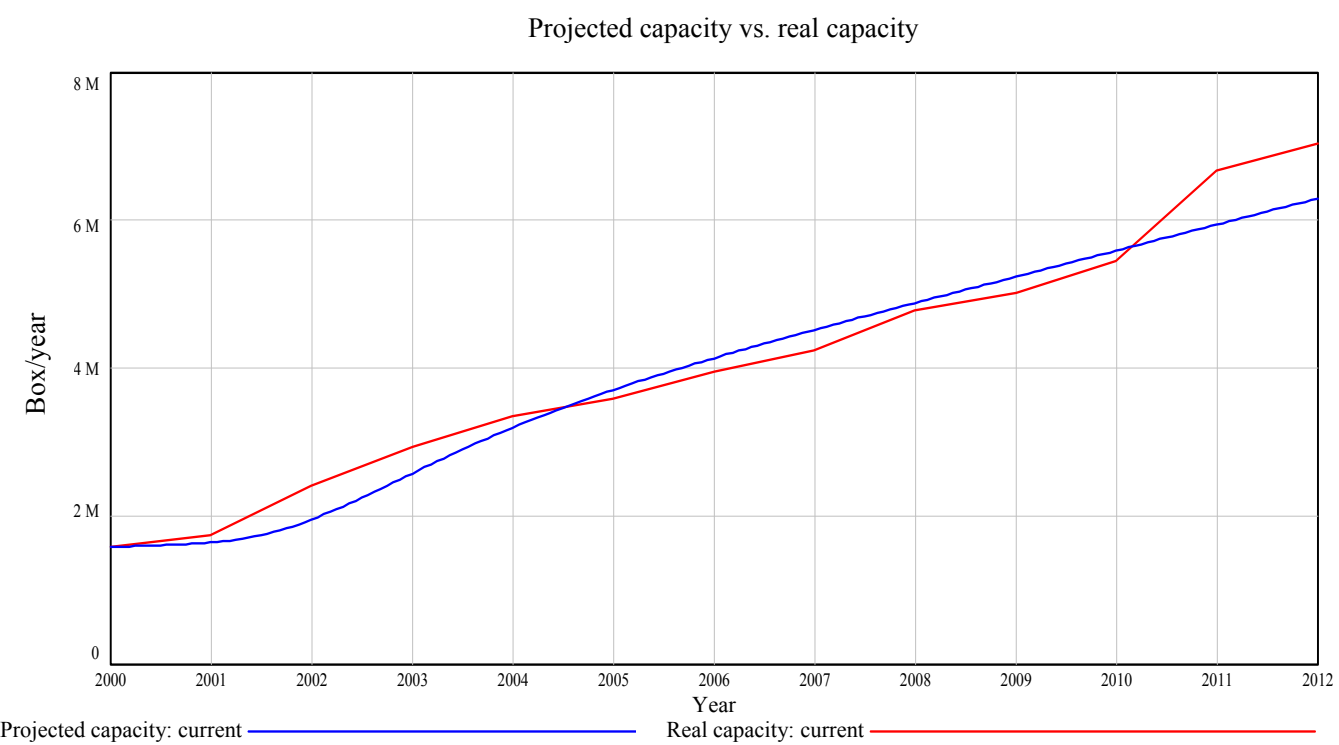

Fig. 4 The projected capacity versus real capacity.

Table 5 The historical fit of the model.

\begin{tabular}{lllll}
\hline \multirow{2}{*}{$R^{2}$} & \multirow{2}{*}{ MAPE } & \multicolumn{3}{c}{ Theil inequality statistics } \\
\cline { 3 - 5 } & & Bias & Unequal variation & Unequal covariance \\
\hline 0.935 & $6.73 \%$ & 0.032 & 0.056 & 0.859 \\
\hline
\end{tabular}

MAPE: mean absolute percent error.

productivity constraint due to the density of containers stacked in the terminal and the average time those containers kept stored in the yard. Such productivity restrain can be due to legal aspects, terminal layout and commercial advantages offered, or even by the interests of the shippers. Thus, the productivity of the terminal depends on the use of its assets, which, in turn, is governed by the density of stored containers that affects the productivity in a non-linear way.

Fig. 5 represents the dynamic model for the container terminals productivity.

Detailed equations of this model are provided below:

(1) Delivery capacity $=$ stored containers/average storage time;

(2) Reception capacity $=$ if then else (projected capacity $>$ real demand (real demand/desired time to meet demand)/effect of capacity utilization on capacity to meet demand, (projected capacity/desired time to meet demand)/effect of capacity utilization on capacity to meet demand);

(3) Stored containers $=$ integ (reception capacity-delivery capacity, initial stored containers);

(4) Effect of capacity utilization on capacity to meet demand $=$ "effect of density of containers stacked in the terminal on its capacity to meet demand. function (capacity utilization)" capacity utilization.

Detailed structure of this model is provided in Fig. 6.

According to the knowledge about the real system and the specific purpose of the model, the model structure and their algorithms seek to demonstrate the validity of its dynamic structure.

\subsection{The Behaviour Accuracy of the Model}

In the container terminals productivity model, the mainly endogenous parameters are real demand, projected capacity, capacity utilization and the effect of capacity utilization on capacity to meet demand, while the mainly exogenous parameters to be considered in the model in order to assess the terminals state productivity over time are desired time to meet demand, initial stored containers and average storage time. 


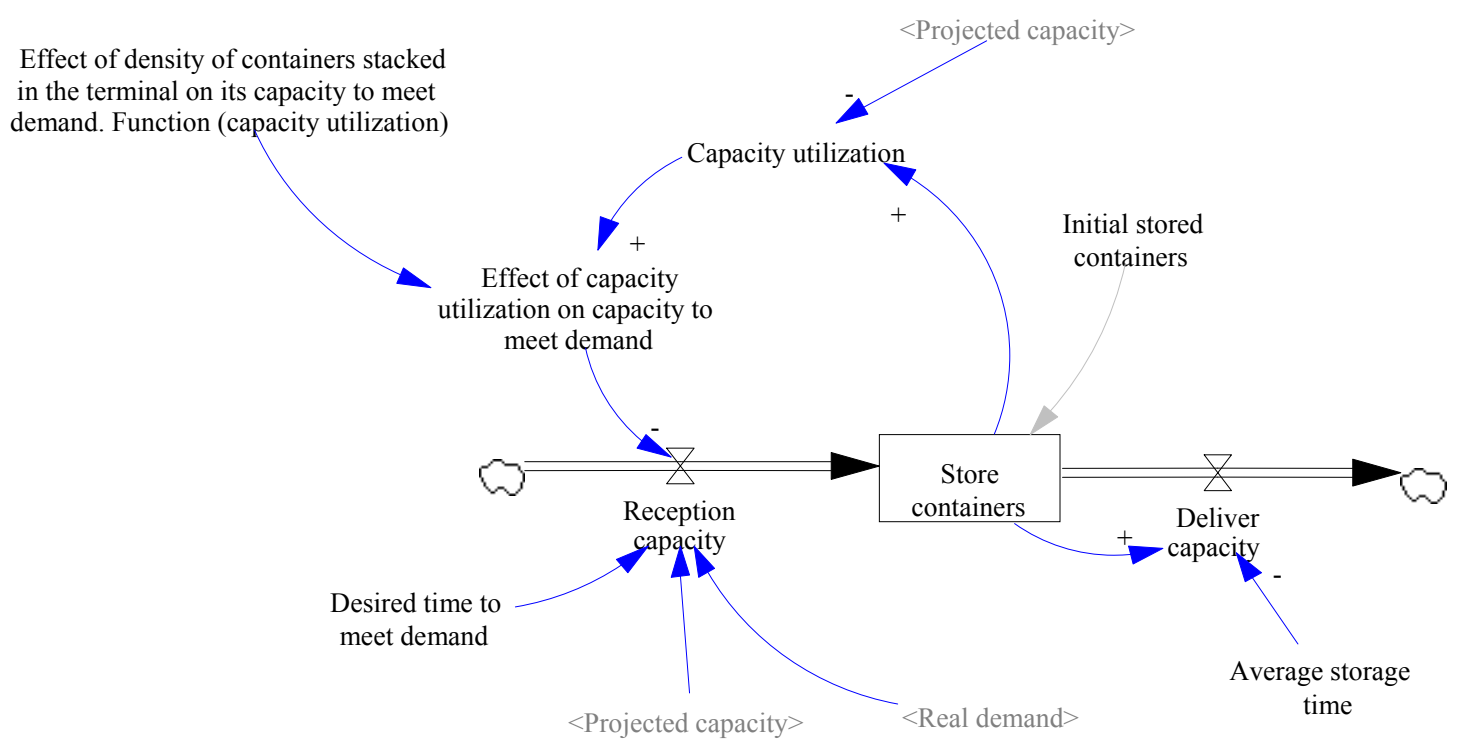

Fig. 5 Structure of productivity model.

(Delivery capacity)
Initial stored containers
Reception capacity Stored containers

Delivery capacity

Average storage time

Fig. 6 Causes tree of productivity model.

The data collected show the endogenous and exogenous parameters, within which are defined the variables of time perception of decision-makers and the non-linear relationship with no variables considered as decision points, as provided below:

(1) time perception:

- average storage time;

- desired time to meet demand;

(2) non-linear relationships:

- effect of capacity utilization on capacity to meet demand.

In reality, data for exact impact of capacity utilization on capacity to meet demand are not readily available because it depends heavily on the handling systems used by the terminals [20, 21]. In this model, therefore, the effect of capacity utilization on capacity to meet demand is exogenously input by calibrating the model in order to simulate the effect of density of containers stored in the yard on the terminal productivity. In this calibration process, on bases of observation of the real world, the relation between the average numbers of moves necessary to perform storage or removing a container in a stock pile up to five boxes of height is estimated.

Fig. 7 shows the effect of container stack density on productivity with the numbers of moves estimated by field observation.

For modelling calibration propose, supported by the system observation, the capacity of a container terminal to handle containers in a year $Y$, is given by its full capacity to handle container at the end of year $Y-1$, because a container terminal just can account initially with new facilities when those are fully ready to use, hence new facilities in process of availability in a year $Y$ just will be fully ready to be used at the beginning of the year $\mathrm{Y}+1$.

The numerical result for the behaviour validity test is show through the Table 6.

The exogenous input variables considered for the model are presented in the Table 7. 
Effect of stack density on productivity

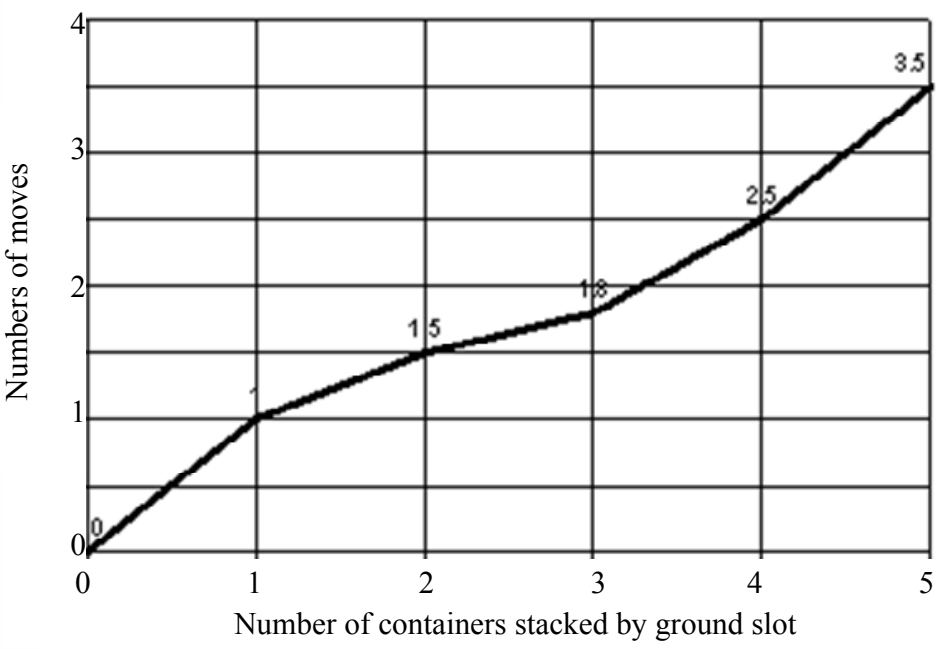

Fig. 7 Effect of stack density on productivity.

Table 6 The actual terminal productivity, according to the terminals layout, operational practices and handling system [20, 27, 28], versus projected productivity.

\begin{tabular}{|c|c|c|c|c|c|c|c|c|c|c|c|c|}
\hline Year & 2001 & 2002 & 2003 & 2004 & 2005 & 2006 & 2007 & 2008 & 2009 & 2010 & 2011 & 2012 \\
\hline $\begin{array}{l}\text { Projected delivery } \\
\text { capacity (box/year) }\end{array}$ & $1,583,000$ & $1,754,000$ & $2,190,000$ & $2,669,000$ & $3,114,000$ & $3,517,000$ & $3,893,000$ & $4,255,000$ & $4,610,000$ & $4,963,000$ & $5,316,000$ & $5,668,000$ \\
\hline $\begin{array}{l}\text { Real delivery } \\
\text { capacity (box/year) }\end{array}$ & $1,533,852$ & $1,698,599$ & $2,349,066$ & $2,859,640$ & $3,253,958$ & $3,489,006$ & $3,848,325$ & $4,121,455$ & $4,647,584$ & $4,876,241$ & $5,296,633$ & $6,495,014$ \\
\hline
\end{tabular}

Table 7 The exogenous input variables.

\begin{tabular}{llll}
\hline Variables & Value & Unit & Description and source \\
\hline Average storage time & 1,028 & Year & $\begin{array}{l}\text { The average time to a container to keep stored in the system studied is considered 10 days. The annual traffic of } \\
\text { containers should flow freely through the terminals at the exact period of one year; However, taking an average } \\
\text { period of storage of 10 days, the container flow is estimated to be around 1.028 years from calibration process }\end{array}$ \\
\hline Desired time to meet demand & 1 & Year & $\begin{array}{l}\text { The desired time to meet demand is assumed to be one year. It is estimated by from the calibration process and } \\
\text { confirm with industry executives }\end{array}$ \\
\hline
\end{tabular}




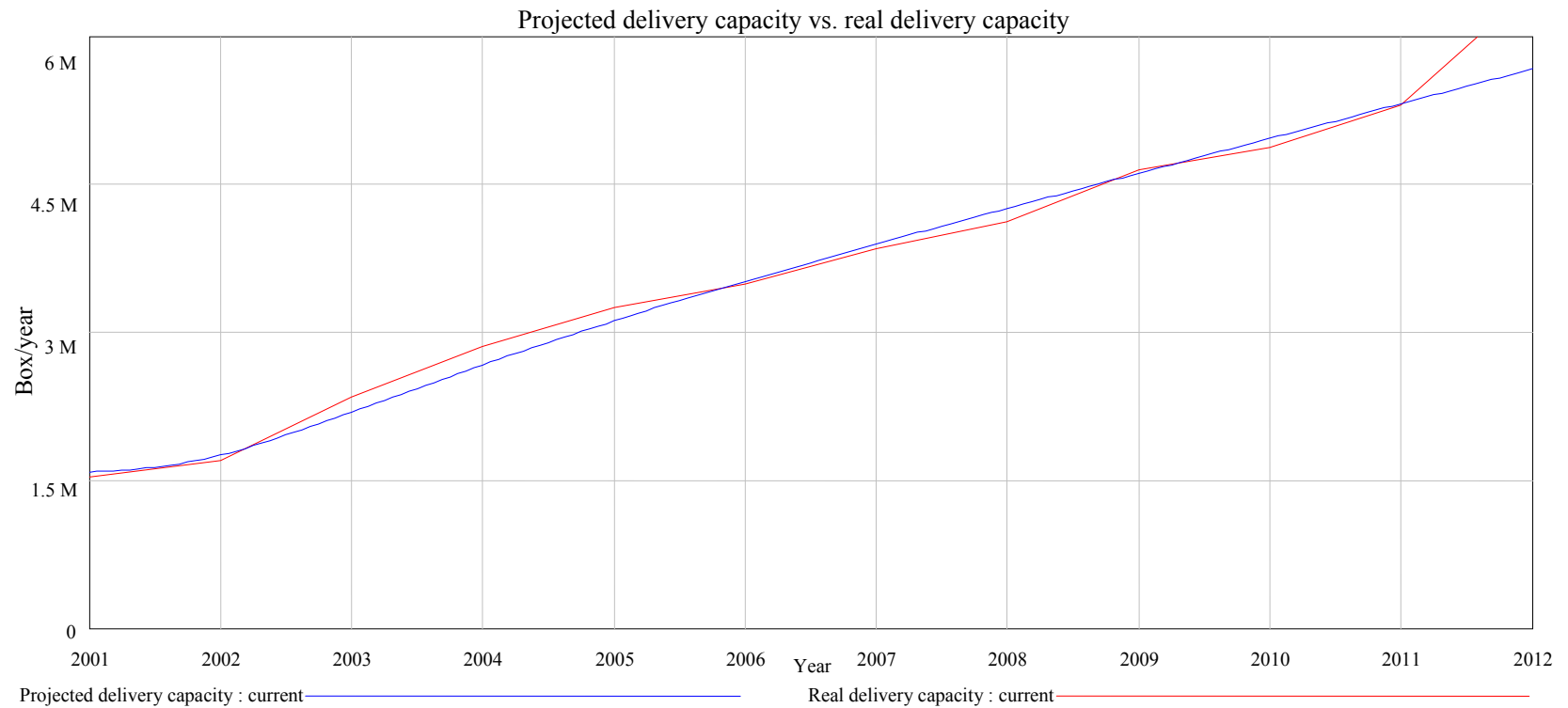

Fig. 8 The projected delivery capacity versus real delivery capacity.

Table 8 The historical fit of the model.

\begin{tabular}{lllll}
\hline \multirow{2}{*}{$R^{2}$} & \multirow{2}{*}{ MAPE } & \multicolumn{3}{c}{ Theil inequality statistics } \\
\cline { 3 - 5 } & & Bias & Unequal variation & Unequal covariance \\
\hline 0.978 & $3.47 \%$ & 0.025 & 0.146 & 0.787 \\
\hline
\end{tabular}

Fig. 8 shows the real delivery capacity of the terminals over time compared with the projected delivery capacity over time obtained by the model simulation.

\subsection{Behaviour Validity Test of the Container Terminal} State Productivity Model

The previous Fig. 8 shows the simulation model tracking the historical data of the system in the assessed period. The results of the behavioural test are shown in Table 8.

The simulation results also show that the model tracks the historical system data quite well. Thus, the correlation of the real delivery capacity to projected delivery capacity is 0.978 . In other words, the correlation clearly indicates the symmetry behaviour of the values obtained in the simulation model with the values collected in the real world. The MAPE between the simulated and actual data are less than $4 \%$, indicating a very close fit of the model to the actual behaviour of the containers terminal state. In addition, the low bias and variation components of the Theil's inequality statistics indicate that errors are unsystematic indicating the model validity concerning the behaviour test.

\section{Conclusions}

This paper presented a system dynamic model to represent the dynamics of productivity and capacity in a group of 18 container terminals associated to ABRATEC. Overall, the model was able to explain the causal linkages driving the dynamic behaviours of the system variables and track the dynamic behaviours of the terminals state in real world from 2000 to 2008, thus increasing the confidence of the model. During the interviewing process, it could be observed that there were not considerable differences of perception regarding to the exogenous variables among the containers terminals' executives throughout the country. Exogenous variables, such as "time to perceive the capacity utilization", "average storage time" and "desired time to meet demand", whose 
perceptions seemed to be not much consistent among them, were resolutely estimated by the calibration process and confirmed with industry executives. The model output could help to predict future development of a container terminal state, since the model approach is able to project the necessary terminals capacity over time in order to cope with a forecasted demand. Consequently, the executives are able to project the assets needs to cope with the market behaviour. The model simulation also gives the opportunity to the terminals decisions maker to tune its mental model regarding to the exogenous variables or even redesign its handling system toward a better productivity and costly effective way, concerning their container terminals within a container terminals state. In other words, the model helps the planners, via simulation, to choose the operational and logistics strategies that best fit to their terminals in a medium or long term period. Given the confidence demonstrated by the model, it can be used as a reference system to test the influence of demand variation over time on a container terminal state capacity needs, according to its overall productivity.

\section{Acknowledgments}

The authors want to acknowledgment ABRATEC, in special thanks to Mr. Sérgio Salomão by the data released and supports to the interview of his associates. The authors is also specially grateful to Mr. Luiz H. Carneiro, president of the MultiRio Terminals, Sidney J. S. Aires, vice president of Suape Port Authority, Alexandre N. Pereira, superintendent of the Port of Itaguaí, Marta F. A. Pires, consultant from Planave Studies and Engineering Projects Ltd., José C. M. Rego, president of the Santos Port Authority, Mr. Darci A. Tartari, planning director of Rio Grande Port Authority and Mr. Antonio Fialho, president of the National Agency of Waterway Transport by their support and interviews.

\section{References}

[1] Sterman, J. 2000. Business Dynamics: System Thinking and Modeling for a Complex World. Boston: Irwin/McGraw-Hill.

[2] Quinn, J. 2005. "European Ports Tackle Congestion." Logistics Management 44: 67-71.

[3] Kim, K., and Kim, H. 1999. "Segregating Space Allocation Models for Container Inventories in Port Container Terminal." International Journal of Production Economy 59: 415-23.

[4] Kim, K., and Kim, H. 2005. "Deriving Decision Rules to Locate Export Containers in Container Yards." European Journal of Operational Research 89-101.

[5] Forrester, J. W. 1961. Industrial Dynamics. Massachusetts: MIT Press.

[6] Senge, P. M. 1997. "The Fifth Discipline." Measuring Business Excellence 1 (3): 46-51.

[7] Doyle, J. K., and Ford, D. N. 1998. "Mental Model Concepts for System Dynamics Research." System Dynamics Review 14 (1): 1-38.

[8] Evangelista, P. 2005. "Innovating Ocean Transport through Logistics and TIC." In International Maritime Transport Perspectives, edited by Leggate, H., McConville, J., and Morvillo, A. Abingdon, Oxon: Routledge.

[9] Davis, T. 1993. "Effective Supply Chain Management." MIT (Massachusetts Institute of Technology) Sloan Management Review 34 (4): 35-46.

[10] Morecroft, J. 2007. Strategic Modeling and Business Dynamics: A feedback Systems Approach. New Jersey: John Wiley \& Sons Inc.

[11] Barlas, Y. 1989. "Multiple Tests for Validation of System Dynamics Type of Simulation Tools." European Journal of Operational Research 42: 59-87.

[12] Barlas, Y. 1996. "Formal Aspects of Model Validity and Validation in System Dynamics." System Dynamics Review 12: 183-210.

[13] Oliva, R. 1995. A Vensim ${ }^{\circledR}$ Module to Calculate Summary Statistics for Historical Fit. System Dynamics Group, MIT. Memo D-4584.

[14] Oliva, R. 2003. "Model Calibration as a Testing Strategy for System Dynamics Models." European Journal of Operational Research 151 (3): 552-68.

[15] Parola, F., and Sciomachen, A. 2005. "Intermodal Container Flows in a Port System Network: Analysis of Possible Growths via Simulation Models." International Journal of Production Economics 97: 75-88.

[16] Marlow, P. B., and Paixão, A. C. 2003. "Measuring Lean Ports Performance." International Journal of Transport Management 1: 189-202.

[17] Marlow, P. B., and Paixão, A. C. 2003. "Fourth Generation Ports: A Question of Agility?" International Journal of Physical Distribution \& Logistics Management 33: 355-76. 
[18] Rios, L., Maçada, A., and Becker, L. 2003. "Modelo de Decisão para o Planejamento da Capacidade nos Terminais de Contêineres." In Proceedings of the XXIII ENEGEP (Encontro Nacional de Engenharia de Produção), 17-29. (in Portuguese)

[19] Rios, L. R., and Maçada, A. C. G. 2006. "Medindo a Eficiência Relativa das Operações dos Terminais de Contêineres do Mercosul Utilizando a Técnica de DEA e Regressão Tobit." In Proceedings of the $30^{\circ}$ Encontro da ANPAD (Associação Nacional em Pesquisa em Administração), 65-81. (in Portuguese)

[20] Thomas, B. J. 1986. Improving Port Performance-Container Terminals: A Policy for Development. Working paper UNCTAD (United Nation Conference for Trade and Development) for training program.

[21] Thomas, B. J. 1996. Measuring Container Terminal Performance. Unit C.6.2 of Portworker Development Program. Working paper of ILO (International Labour Office).

[22] Santos, R., and Haddad, E. 2007. "Eficiência Relativa dos Portos Brasileiros: Uma Análise Regionalizada.” Research paper of University of São Paulo. (in Portuguese)

[23] Robinson, R. 2002. "Ports as Elements in Value-Driven Chain Systems: The New Paradigm." Maritime Policy and Management 29: 241-55.

[24] Prater, E., Biehl, M., and Smith, M. A. 2001. "International Supply Chain Agility, Tradeoffs between Flexibility and Uncertainty." International Journal of Operational \& Production Management 21 (5/6): 823-39.

[25] ABRATEC (Associação Brasileira dos Terminais de Contêineres de Uso Público (in English: Brazilian Association of Public Container Terminals)). 2004. Containers Terminals Performance 2004. Rio de Janeiro: ABRATEC.

[26] ABRATEC. 2008. Containers Terminals Performance 2008. Rio de Janeiro: ABRATEC.

[27] CEL (Centre of Logistics Studies): Federal University of Rio de Janeiro. 2008. Análise e Avaliação dos Portos Brasileiros. Rio de Janeiro: CEL. (in Portuguese)

[28] CEL (Centre of Logistics Studies): Federal University of Rio de Janeiro. 2008. Intermodalidade de Contêineres no Brasil. Rio de Janeiro: CEL. (in Portuguese) 